\title{
Seasonal Variation and Environmental Properties of Southward Propagating Mesoscale Convective Systems over the Bay of Bengal
}

\author{
Tomoki Miyakawa* and Takehiko Satomura \\ Graduate School of Science, Kyoto University, Kyoto, Japan
}

\begin{abstract}
We tracked fast moving mesoscale convective systems (MCSs) over the Bay of Bengal, counted their numbers, and analyzed the characteristics of wind and geopotential fields of when such MCSs propagate southward over the Bay. We used hourly TBB data of GMS5 IR1 (1996-2001, AprilOctober) for the tracking, and used 6-hourly ECMWF 40 year re-analysis data to analyze the characteristics of wind and geopotential fields.

The numbers of fast moving MCSs were as follows: April 11/56 (20\%); May 46/103 (45\%); June 50/173 (29\%); July 33/160 (21\%); August 27/125 (22\%); September 8/61 (13\%); October $8 / 67(12 \%)$; total 183/745 (25\%). The fractions represent (number of southward propagating MCSs)/(total number of MCSs), and the numbers inside the parentheses are the percentages of the southward propagating MCSs.

We concluded that fast southward propagation of MCSs tends to occur when a trough exists over the Bay at the height of $600 \mathrm{hPa}$, and the wind shear between the surface and the $600 \mathrm{hPa}$ height has a southward component. We also found that propagation towards other directions is related with eddy disturbances over the Bay.
\end{abstract}

\section{Introduction}

The Bengal area is one of the regions with the world's heaviest rainfall. For example, Bangladesh, which lies in the northern end of the Bay of Bengal, has the maximum climatic rainfall of approximately $6000 \mathrm{~mm}$ during the summer monsoon season (Matsumoto et al. 1996) and suffers from flood every year. Understanding the progress and the activity of the summer monsoon is essential to predict such disasters caused by heavy rainfall.

Existence of both northward and southward cloud movements are known over the Bay of Bengal. Two preestablished northward movements are northward components of Madden Julian Oscillation (Yasunari 1979) and those of 10-15 day intra-seasonal oscillation (Annamalai and Slingo 2001): They are key factors of onsets and activebreak-cycles of the summer monsoon. On the other hand, southward movements were firstly found in 1999 during JASMINE (Joint Air-Sea Monsoon Interaction Experiment) which was held in the Bay of Bengal (Webster et al. 2002). Although there are a few more studies about the southward cloud movements around or over the Bay (Zuidema 2003; Yang and Slingo 2001; Kataoka and Satomura 2005), the southward movements are not as well- documented as northward movements. However, it is possible that the activity of the southward propagating MCSs plays a role in the progress of summer monsoon onset or the intraseasonal variation of the summer monsoon. Therefore, it would be interesting to study the southward propagation of MCSs by expanding the time and spatial extents.

A quick look at satellite images indicates a tendency of

Corresponding author: Tomoki Miyakawa, Center for Climate System Research, University of Tokyo, 5-1-5, Kashiwanoha, Kashiwa-shi, Chiba, 277-8568 Japan.

E-mail: miyakawa@ccsr.u-tokyo.ac.jp.

*Present affiliation: Graduate School of Science, University of Tokyo, Tokyo, Japan. (02006, the Meteorological Society of Japan.



Fig. 1. A snap shot of a southward propagating MCS on 02 UTC 9 May 2001. The color contours indicate the TBB (K) observed from GMS5.

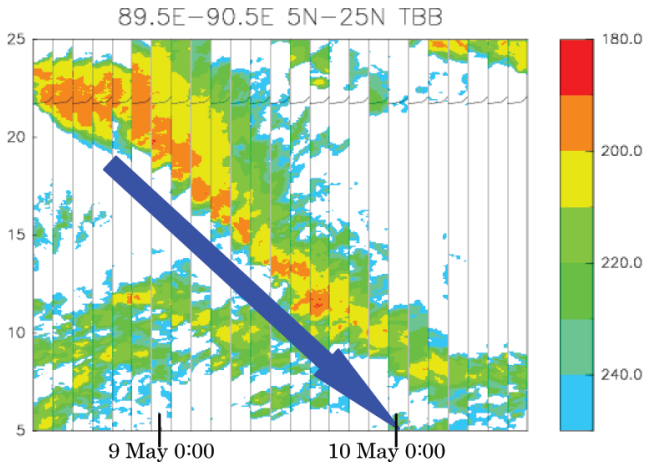

Fig. 2. A time-latitude cross section of the red shaded area in Fig.1. The propagation speed $10 \mathrm{~m} \mathrm{~s}^{-1}$ is indicated by the blue arrow.

southward propagation occurring in early- or pre-summer monsoon. Figure 1 is an example of a southward propagating MCS, which was observed during 8-10 May in 2001 by the GMS5 IR1 (infrared 1 channel $10.5 \mu \mathrm{m}-11.5 \mu \mathrm{m})$. Its horizontal scale is over $500 \mathrm{~km}$ both in the zonal and meridional directions. The cloud top temperature near the center of the MCS is lower than $200 \mathrm{~K}$, which indicates the cloud top height is higher than $15 \mathrm{~km}$ (according to ECMWF 40 year re-analysis data). Figure 2 is a timelatitude cross section of the area shaded red in Fig. 1. It is apparent that the cloud system moves about $10^{\circ}(\sim 1100$ $\mathrm{km}$ ) southward in 24 hours (00 UTC on 9 to 00 UTC on 10 May). The propagation speed of the system is estimated to be approximately $10 \mathrm{~m} \mathrm{~s}^{-1}$.

During JASMINE, Webster et al. (2002) encountered 4 fast moving $\left(>10 \mathrm{~m} \mathrm{~s}^{-1}\right)$ MCSs during 21-26 May at $11.2^{\circ} \mathrm{N}$ $89.3^{\circ} \mathrm{E}$. All the observed MCSs propagated over $800 \mathrm{~km}$ southward. They analyzed radiosonde wind profile data and C-band Doppler radar data at point $11.2^{\circ} \mathrm{N} 89.3^{\circ} \mathrm{E}$ and pointed out that, interestingly, the southward propagating 
MCSs moved in directions orthogonal to the wind direction at all levels. Zuidema (2003) analyzed NCEP reanalysis data of the heights $850 \mathrm{hPa}$ and $300 \mathrm{hPa}$, and described that the wind directions of both heights were perpendicular to the direction of the MCSs' propagation. Zuidema (2003) also analyzed the Meteosat-5 TBB data in 1988 and 1999, and counted the number of propagating MCSs.

However, the seasonal variations of these southward MCSs remained unclear. Further, the background atmospheric conditions were not yet sufficiently investigated. The mechanism of the MCSs' peculiar capability to propagate fast in the direction normal to the wind direction remained a question too.

The purpose of this study is to survey the frequency of southward propagation of MCSs and the preferable atmospheric conditions for the southward propagation of MCSs. An insight to the mechanism may be thereby produced.

\section{Data and method}

\subsection{GMS5 data}

The hourly GMS5 data of April-October 1996-2001 were used. These data were downloaded from Kochi University (http://weather.is.kochi-u.ac.jp/). Horizontal resolutions of these data are $0.05^{\circ}$. We smoothed these data by averaging 4 adjacent grids in order to reduce the amount of computing and gained a dataset with horizontal resolution of $0.1^{\circ}$ in a rectangular region of $70^{\circ}-105^{\circ} \mathrm{E}$, $5^{\circ} \mathrm{S}-40^{\circ} \mathrm{N}$. Unfortunately, the data of 22-31 May 1999 are missing, which include the term Webster et al. (2002) analyzed. In other months, data are not lost largely.

\subsection{ECMWF 40 Year Re-analysis (ERA40) data}

In order to analyze the characteristics of the background atmospheric conditions, ERA40 data downloaded from the official homepage of ECMWF (European Centre for Medium-ranged Weather Forecasts http://data.ecmwf.int/ data/d/era40_daily) were used. These data are 6-hourly and have horizontal resolution of $2.5^{\circ}$. We used a rectangular region of $50^{\circ} \mathrm{E}-130^{\circ} \mathrm{E}, 10^{\circ} \mathrm{S}-40^{\circ} \mathrm{N}$, and 13 height levels between $1000 \mathrm{hPa}-100 \mathrm{hPa}$. The atmospheric components we used were geopotential, zonal wind, and meridional wind. Data of April-October 1996-2001 were used.

\subsection{Tracking method}

We identified and tracked cloud systems by the following procedure:

a. An MCS is identified only when the area of closed contour of $\mathrm{TBB}<215 \mathrm{~K}$ exceeds 200 pixels (approximately $150 \times 150 \mathrm{~km}^{2}$ ). For each MCS, its area and the location of the centroid are determined.

b. If the areas of MCSs in subsequent images overlap more than $50 \%$ of the area of the smaller MCS, we decide that they are the same MCS and determine the track of the centroid.

c. If an MCS survives longer than 10 hours, and if the averaged propagation speed (calculated from the time and positions of the first and last time of their lives) exceeds $20 \mathrm{~km} \mathrm{~h}^{-1}$, it is counted and categorized into propagation directions. The propagation speed faster than $20 \mathrm{~km} \mathrm{~h}^{-1}$ is not far off from those of MCS's studied by Webster (2002).

\subsection{Composite of background atmospheric fields}

For each MCS that was identified and counted by the tracking method, the background atmospheric fields are calculated from the ERA40 data by averaging all the 6 hourly data in the system's lifetime. Then the deviation from climatological values are calculated.

\section{Results}

The numbers of fast moving MCSs in 16 directions in each month are shown in Fig. 3. Hereafter, we call MCSs

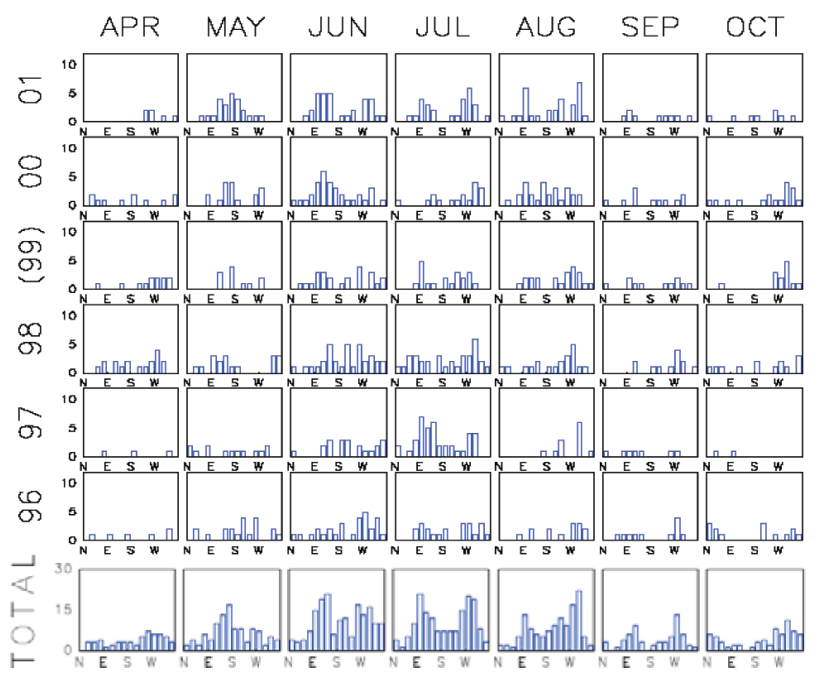

Fig. 3. Numbers of fast moving MCSs for each direction (direction is divided in to 16 ; each bar has a width of $22.5^{\circ}$, starting with N-NNE, $0^{\circ}-22.5^{\circ}$ ). Note that data of 22-31 May 1999 are missing.

with propagation directions between southeast and southwest $\left(90^{\circ}\right.$ width) as southward propagating MCSs, for example. The numbers of the southward propagating MCSs during the analyzed period are as follows: $11 / 56(20 \%)$ in April; 46/103 (45\%) in May; 50/173 (29\%) in June; 33/160 (21\%) in July; $27 / 125(22 \%)$ in August; 8/61 (13\%) in September; $8 / 67$ (12\%) in October; $183 / 745$ (25\%) in total. The fractions represent (number of southward propagating MCSs)/(total number of MCSs), and numbers inside the parenthesis are the percentage of southward propagating MCSs. Although the mature period of the summer monsoon is June-August, MCSs are more likely to propagate southward in earlier months of the summer monsoon season, May and June. Note that the data of 22-31 May 1999 are lost and Fig. 3 does not include the 4 cases Webster et al. (2002) analyzed. Therefore the actual number of southward propagating MCSs in May should be at least 50 .

Distribution of the propagating direction varies from year to year. In years 1996, 1999, 2000, and 2001, the MCSs had the highest tendency $(45 \%-58 \%)$ to propagate southward in May; in years 1997 and 1998, the month of highest tendency $(38 \%-43 \%)$ to propagate southward was June. In total, MCSs had the highest tendency (45\%) to propagate southward in May. In July, August, and September, there were double peaks (eastward and westward); June had combined features of both.

In a time-altitude cross section of 2001 ERA40 meridional wind data averaged over the Bay of Bengal, we found an area of northerly wind between $750 \mathrm{hPa}-500 \mathrm{hPa}$ in May, having its maximum axis near the $600 \mathrm{hPa}$ height (not shown). Therefore we focused mainly on the $600 \mathrm{hPa}$ height, while most preceding studies conventionally focus on $500 \mathrm{hPa}$. Figure 4 shows the $600 \mathrm{hPa}$ composite background fields of southward propagating MCSs. There is a trough (indicated with orange line) over the Bay of Bengal, and northwesterly wind flows into the northwest of the Bay. In the composite of background fields at $850 \mathrm{hPa}$, no rthwest-southeast monsoon trough exists with the axis located approximately from Delhi $\left(28.5^{\circ} \mathrm{N}, 77^{\circ} \mathrm{E}\right)$ to Calcutta $\left(22.5^{\circ} \mathrm{N}, 88^{\circ} \mathrm{E}\right)$; the Bay of Bengal is covered with southwesterly monsoon flow (not shown). The Bay is covered with easterly monsoon flow at $300 \mathrm{hPa}$.

Figure 5 shows the deviations of composited wind and geopotential from the climatological values. Hatches (dots, horizontal lines and vertical lines) indicate areas where deviations are statistically larger than 99\% significance level. It is apparent that a trough type deviation exists over 


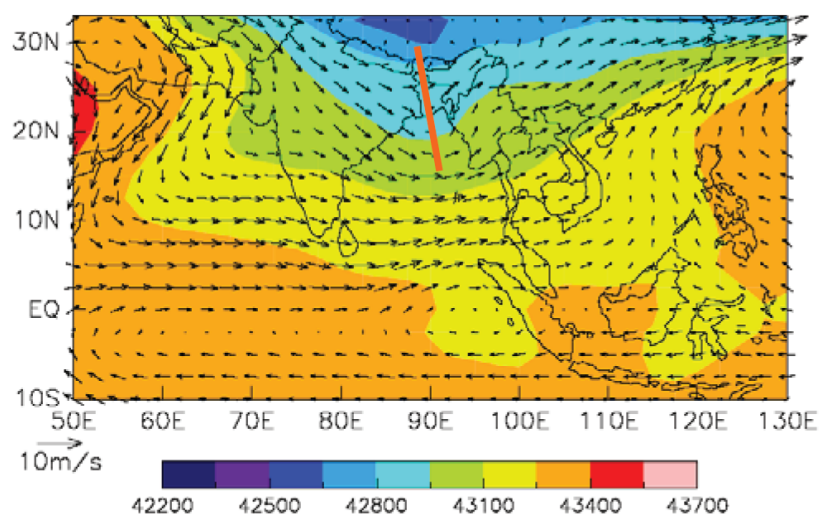

Fig. 4. Composite background fields of southward propagating MCSs at 600 hPa height. Color contour stands for geopotential, and the vectors for horizontal wind. Orange line indicates the axis of a trough.

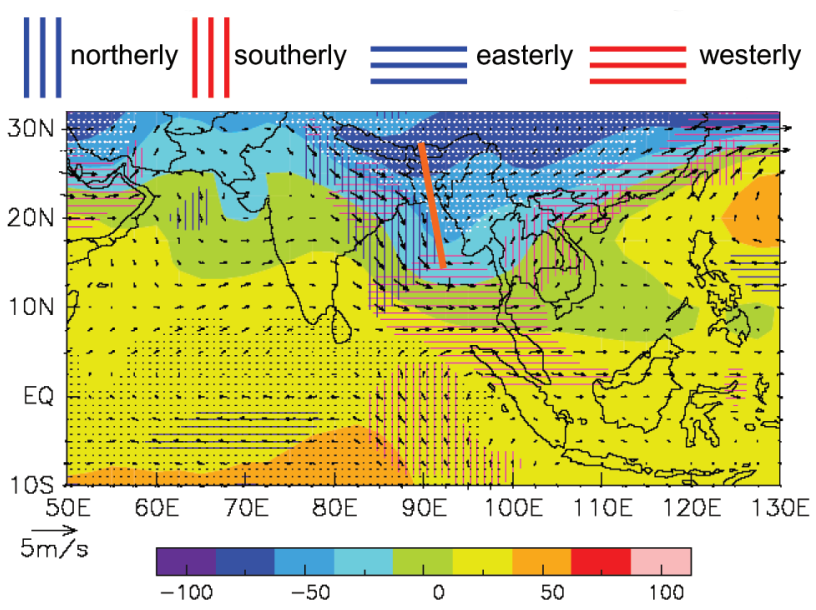

Fig. 5. Same as Fig.4 except that it is the deviation from the climatological values. Hatches of white (black) dots indicate negative (positive) deviation of geopotential statistically larger than 99\% significance level. Blue and red vertical lines indicate northerly and southerly deviations, respectively, and blue and red horizontal lines indicate easterly and westerly deviations, respectively, statistically larger than 99\% significance level. Orange line indicates the axis of a trough.

the Bay of Bengal. Noting that this composite includes more members of May-June than July-August, the large deviation seen in the northern parts (e.g., Nepal, Tibet, and China) may be explained by the seasonal change of climatology associated with the northward shift of the Subtropical Jet. However, the data of the northern mountain areas must be handled with care because many peaks are higher than $600 \mathrm{hPa}$ level.

Figures $6 \mathrm{a}$ and $6 \mathrm{~b}$ are simplified images of the structure of wind around the southward propagating MCS. Webster et al. (2002) and Zuidema (2003) pointed out the upper easterly and lower westerly winds. However, they did not sufficiently describe the northerly component of the midlevel wind.

In some cases, northerly component of the $600 \mathrm{hPa}$ wind is as strong as $15 \mathrm{~m} \mathrm{~s}^{-1}$, which seems strong enough to cause the southward propagation of MCSs by direct drifting. However, the southward propagation speeds of MCSs are not always nearly equal to the northerly component of the $600 \mathrm{hPa}$ wind. The horizontal location of the $600 \mathrm{hPa}$-northwesterly-wind does not always precisely overlap with the track of southward propagating MCSs

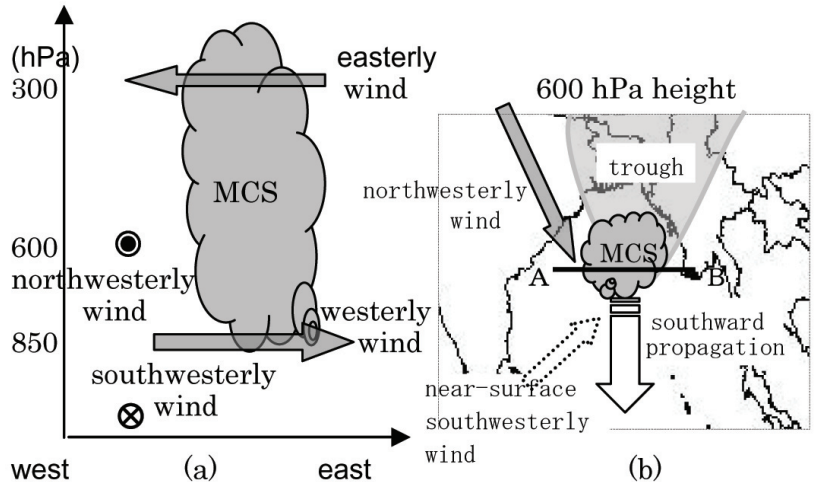

Fig. 6. Simplified images of the structure of wind around a southward propagating MCS. (a) is the longitude-height cross section at line A-B in (b). Northwesterly and southwesterly wind is indicated with $\bigcirc$ and $\otimes$ respectively in (a).

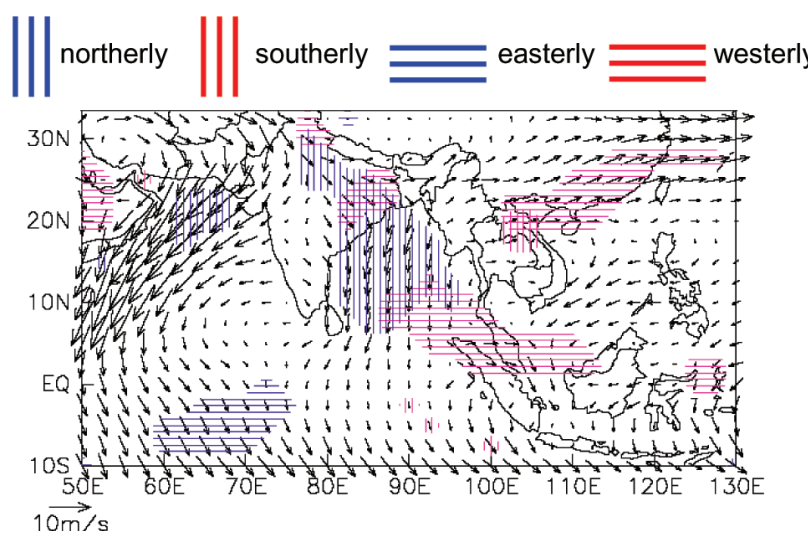

Fig. 7. Same as Fig. 5. except that it is a composite $600 \mathrm{hPa}-$ $1000 \mathrm{hPa}$ shear map drawn for background fields of southward propagating MCSs.

either. These indicate that direct drifting by the northerly component of $600 \mathrm{hPa}$ wind is not the only factor that controls the propagation direction and speed of the MCSs.

In a recent study, Shumacher and Johnson (2005) analyzed the environmental properties of certain types of MCSs in North America. They investigated the mid- and low-level wind shear $(500 \mathrm{hPa}-925 \mathrm{hPa})$ and low- and surface-level wind shear $(925 \mathrm{hPa}-1000 \mathrm{hPa})$, and described the relationships between the wind -shear directions and the propagation direction of the MCSs. Here, we also focused on the vertical wind shears, though we simply analyzed the wind shear between $600 \mathrm{hPa}$ and $1000 \mathrm{hPa}$, for the magnitude of the $925 \mathrm{hPa}-1000 \mathrm{hPa}$ wind shear was small compared to that of $600 \mathrm{hPa}-1000 \mathrm{hPa}$. A closer and more detailed analysis of the wind shears and comparative discussions with Shumacher and Johnson (2005) will be done in a forthcoming paper.

Figure 7 is the composite shear map of $600 \mathrm{hPa}-1000$ $\mathrm{hPa}$ (surface wind subtracted from $600 \mathrm{hPa}$ wind) of background fields of southward propagating MCSs. The entire Bay is covered with strong vertical northerly shear (the hatch with blue vertical lines). The horizontal location of the northerly $600 \mathrm{hPa}-1000 \mathrm{hPa}$ shear overlaps with the tracks of southward propagating MCSs (not shown) more precisely than the horizontal location of $600 \mathrm{hPa}$ northwesterly-wind does. However, the reason for this is yet to be discovered.

We have focused on atmospheric conditions of southward propagating MCSs. Let us now quickly look at those 


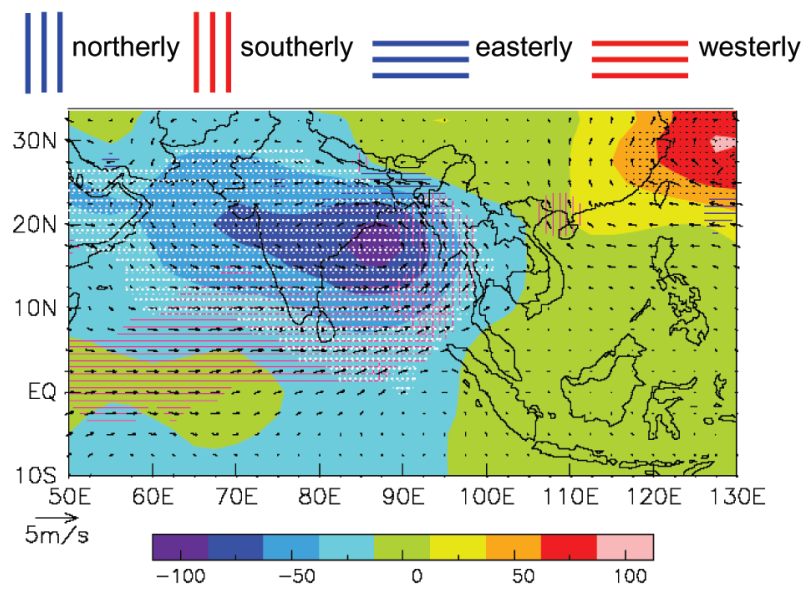

Fig. 8. Same as Fig. 5 except that it is drawn for background fields of northward/eastward/westward propagating MCSs.

of MCSs propagating to other directions. Figure 8 represents the deviation of a composite field of northward, eastward, and westward moving MCSs altogether. It is noteworthy that the background atmospheric conditions of north, east, and westward moving MCSs share a common characteristic that an eddy-like deviation appears over the Bay. The center of the eddy is located near a place named Point Palymras, where centers of organized convective disturbances such as monsoon depressions are observed most frequently (Zuidema 2003). The eddy-like deviation appears at all heights through low- to mid-troposphere, which is consistent with the vertical structure of monsoon depressions. The large deviation extending to the west coast of India probably corresponds to the west-northwestward movement of monsoon depressions.

\section{Summary and discussion}

By applying pattern recognition and tracking method to the TBB data of GMS5, the seasonal and inter-annual variations of the fast southward moving MCSs over the Bay of Bengal were described. It is interesting to note that the peak of the southern propagation occurs in May and June earlier than the middle of the rainy season. Particularly in May, nearly half of the MCSs are identified as those propagating southwards.

Composite analysis of atmospheric conditions was performed for southward and also non-southward propagating MCSs. Furthermore, by investigating the deviation of atmospheric conditions from climatological values, it was revealed that southward propagation occurred preferably in the condition where a trough existed at the $600 \mathrm{hPa}$ level over the Bay of Bengal. Along the trough, winds with a northerly component blew into the Bay.

The result in this paper does not necessarily conflict with the radiosonde and C-band Doppler radar data of Webster et al. (2002). Daily mean $600 \mathrm{hPa}$ composites of ERA40 geopotential data of 22-26 May 1999 indicate that the point $11.2^{\circ} \mathrm{N} 89.3^{\circ} \mathrm{E}$ where they gained the data was near the southern end of a $600 \mathrm{hPa}$ trough where northerly components of the $600 \mathrm{hPa}$ winds are small (not shown). In fact, the southward propagations also become vague (Fig. 14 in Webster et al. 2002).

The northerly components were sometimes as strong as $15 \mathrm{~m} \mathrm{~s}^{-1}$. In such cases the northerly wind is strong enough to directly drift the cloud systems southward. However, there were many cases where the propagating speed was too fast compared to the wind speed or propagating direction was not quite consistent with the wind direction. This inconsistency indicates that the propagation direction and speed of most of the MCSs are controlled not only by the direct drifting by northerly wind, but also by a combination with other factors such as rebuilding of convective cells provoked by cold outflows from the system itself, which is one of typical cases in various propagation of MCSs (e.g., Corfidi 2003).

It is also found that, though the reason is not clear, the tracks of southward propagating MCSs overlap more precisely with the horizontal location of the northerly 600 $\mathrm{hPa}-1000 \mathrm{hPa}$ vertical shear than with that of the $600 \mathrm{hPa}$ northerly wind.

In cases of MCSs propagating toward directions other than southwards, the composited background conditions showed the eddy-like deviation near Point Palymras. Therefore it is concluded that the background field of southward propagating MCSs is distinct from that of MCSs propagating towards other directions. The mechanism of the southward propagation of MCSs closely related with the $600 \mathrm{hPa}-1000 \mathrm{hPa}$ northerly shear remains to be discovered.

The reason why troughs appear at $600 \mathrm{hPa}$ is a remarkable theme for future work, for it may be related with the seasonal progress of the monsoon onset. An interseting fact that may support this presumption is that in 1997 (a double onset year), the seasonal development was slower than usual and the peak of southern propagation of MCSs was late; the peak was in June instead of May.

\section{Acknowledgments}

The authors are grateful to the members of Climate Environment Laboratory and Climate Physics Laboratory, Kyoto University, for their constructive comments. We utilized the algorithm of the tracking method developed by Okumura et al. (2003). We downloaded the GMS data from Kochi University, and the ERA40 data from ECMWF homepage.

\section{References}

Annamalai, H., and J. M. Slingo, 2001: Active/break cycles: diagnosis of the intra-seasonal variability of the Asian Summer Monsoon. Clim. Dyn., 18, 85-102.

Corfidi, S. F., 2003: Cold pools and MCS propagation: Forecasting the motion of downwind-developing MCSs. Wea. Forecasting, 18, 997-1017.

Shumacher, R. S., and R. H. Johnson, 2005: Organization and environmental properties of extreme-rain-producing mesoscale convective systems. Mon. Wea. Rev., 133, 961-976.

Kataoka, A., and T. Satomura, 2005: Numerical simulation on the diurnal variation of precipitation over northeastern Bangladesh: A case study of an active period 14-21 June 1995. SOLA, 1, pp. 205-208.

Matsumoto, J., 1997: Seasonal transition of summer rainy season over Indochina and adjacent monsoon region. Adv. Atmos. Sci., 14, 231-245.

Okumura, K., T. Satomura, and W. Khantiyanan, 2003: Diurnal variation of precipitation by mesoscale systems: Radar observation in northern Thailand. Geophys. Res. Lett., 30, 2073, doi: 10.1029/2003 GL018302.

Webster, P. J., E. F. Bradley, C. W. Fairall, J. S. Godfrey, P. Hacker, R. A. Houze Jr., R. Lukas, Y. Serra, J. M. Hummon, T. D. M. Lawrence, C. A. Russell, M. N. Ryan, K. Sahami, and P. Zuidema, 2002: The JASMIN pilot study. Bull. Amer. Meteor. Soc., 83, 1603-1630.

Yang, G. Y, and J. Slingo, 2001: The diurnal cycle in the Tropics. Mon. Wea. Rev., 129, 784-801.

Yasunari, T., 1979: Cloudiness fluctuations associated with the northern hemisphere summer monsoon. J. Meteor. Soc. Japan, $57,227-242$.

Zuidema, P., 2003: Convective clouds over the Bay of Bengal. Mon. Wea. Rev., 131, 780-798.

Manuscript received 27 March 2006, accepted 26 May 2006

SOLA: http://www.jstage.jst.go.jp/browse/sola/ 